\title{
Social Interaction in Knowledge Acquisition: Advanced Curriculum Critical Review of Studies Relevant to Social Behavior of Infants
}

\author{
Igor Val. Danilov \\ Academic Center for Coherent Intelligence
}

The discussion paper investigates other researches that observe social behavior in studies with no communication between subjects. This current analysis reviews several studies on social phenomenacategorization of words, preference of faces and even race - in newborns and 3- to 4-months-old infants and complements their findings. The review states that newborns and young infants are not able to independently classify phenomena from social reality and perceptually interact with adults effectively enough to understand the meanings of social phenomena on their own. The paper concludes that the social behavior of infants is driven by adult social learning through non-perceptual social interaction between them.

Keywords: coherent intelligence, interpersonal perception, interpersonal synchrony, mirror system, nonperceptual social interaction, problem-based learning, social cognition, socialization, synchronization, theory of mind

\section{INTRODUCTION}

Comprehension and interaction with social reality are key issues for the cognitive development. They form many social skills such as language and knowledge acquisition, manifesting themselves practically in social behavior. The question of how and when the meanings of first phenomena of reality are acquired by an empty mind can reveal the ontogenesis of social interaction (i.e., the question of how and when human beings begin behaving socially). The overarching goal of this study is to explore the essence of social interaction by studying social behavior of newborns and infants. Numerous researches were aimed on studying when human beings start behaving socially (Danilov, 2020); other studies explore categorization of social phenomena - words, faces and even race - in newborns and 3- to 4-month-olds infants. This review in particular is designed to investigate more specific questions of what helps newborns and infants behaving socially during experiments, where these human beings do not yet know enough meanings of social phenomena to socially behave and with no communication between subjects. Section II explains the modern knowledge about acquisition of first social phenomena in infants.

The Section III reviews articles which studied social behavior among infants through facial recognition. Section IV presents the finding about word categorization in infants. Section V elaborates all findings from Section III and Section IV, describing their meaning. Sections VI and VII present some ideas on advanced curriculum, based on the non-perceptual interaction. 


\section{ACQUISITION OF SOCIAL PHENOMENA}

Key issues in selecting studies for this review were behavioral parameters belonging to the division between physiological reactions and social behavior of newborns and infants (i.e., differences between innate or learned from the environment actions.) Developmental psychologists consider that initial learning occurs within a shared referential context through repetitive multimodal routines, which allow infants to utilize current knowledge to predict and acquire new meanings (Tomasello, 2003). Danilov and Mihailova (2019) argued that acquisition of knowledge is mainly based on discovery of new key relationships between cause and effect within prior knowledge, and/or on the opening links between elements of prior knowledge and new information domain. 'This means that the acquisition of initial words also requires infants to be able to also demonstrate some basic knowledge on the social reality around - specific basic knowledge of their particular group, considering the existence of about 6,000 languages in even more groups and communities, all with their unique social reality - as well as needs efficient communication, which is a reciprocal exchange of mutually intended meanings (Danilov \& Mihailova, 2019, p. 147).' That is the issue of 'current knowledge' (i.e., assimilation of the first or initial meanings of social phenomena) is still a focus of discussions. Initial learning theories are developed within the framework of two core approaches: the innate knowledge and the acquired knowledge from the environment. Some recent studies attempted to address the problem of acquiring the initial social phenomena; they suggest that infants exhibit some general sensitivities and expectations at the onset of language acquisition (this later could be adjusted to the particular language environment that the young infants find around) (Waxman \& Leddon, 2010) and/or expect to learn reference information through ostensive cues (Csibra \& Gergely, 2009). For instance, Waxman and Leddon (2010) have proposed that infants begin the task of word learning equipped with an initially general and universal expectation. The expectation is then formed by the structure of the particular language. They then grow sensitivity to these perceptual cues. This allows them to separate two classes of words: open classwords (nouns, adjectives, verbs) and closed class words, including determiners and prepositions (Waxman \& Leddon, 2010). According to Csibra and Gergely (2009), infants are sensitive to certain ostensive cues. Their theory of natural pedagogy suggests that infants expect to learn reference information through signals that relatives direct to them. For example in case of young infants these ostensive cues manifest themselves following the gaze (Csibra \& Gergely, 2009). Danilov and Mihailova (2019) have questioned these theories above following recent researches and concluding that: The perceptual sensitivities and expectations that Waxman and Leddon (2010) proposed, and/or ostensive cues Csibra and Gergely (2009) are not able alone to fill infants' personal reality with a sufficient number of phenomena in order to start categorization (Danilov \& Mihailova, 2019). The latest study of Silverstein et al. (2019) supports the above conclusions of Danilov and Mihailova (2019), also refuting the idea of core role of ostensive signals in initial learning of infants. The approach to explain the acquisition of initial social phenomena by imitation is also unconvincing. Newborns and 3- to 4-month-olds infants are not able to imitate social behavior, since 'infants do not imitate others until their second year, and that imitation of different kinds of behaviour emerges at different ages (Jones, 2009).'

Another approach, the one from innate knowledge to the problem of acquiring initial social phenomena, is based on the idea of sound-to-meaning correspondences (Rizzini, 2018; Namy \& Nygaard, 2008). Rizzini introduced an idea of 'visible-expressive code that precedes the use of phonetic codes (Rizzini, 2018)'. In his study of the sense of articulate-oral gestures people use phonetic sounds to convey meaning. Sounds correspond to oral gestures that create them, which in turn substitute behavioral responses to internal and external events. This means practically that articulate-oral gestures have universal meanings through innate visible-expressive code. This theory also suggests a mechanism for collecting social phenomena by newborns: actual physiological responses of the newborns to internal and external events are superimposed in their neural circuits on the innate visible-expressive codes. If they coincide, then they are filled with meanings and stored. These meaningful gestures remain in their operative disposal, as a library of the same events. The set of articulate-oral gestures, created in such a manner, becomes an

adequate response to the actual needs of their social reality. This means that newborns arrive in social life with neurological tools suitable for behavioral responses, and are able to use them carefully and efficiently 
depending on the occurrence. This process leads to neurological growth of newborns with the help of more and more effective symbolization through the visible-expressive codes (Rizzini, 2018). This very welldeveloped theory explains part of the social interaction that occurs via unconscious communication throughout life. However the acquisition of initial social phenomena by newborns can be explained limitedly within the framework of above noted innate visible-expressive code and/or any other embodied cognition approach, because this approach contains of difficulties:

(i) lack of empirical evidence and, probably, the impossibility of ever proving the standpoint of innate knowledge on social phenomena.

(ii) absence of mechanism that can explain such innate transfer of knowledge based on biology and/or laws of physics. Social behavior is influenced by many environmental factors and also by psychological traits of individual, the heritability of which is caused by many genes of small effect (Plomin et al., 2016). Obviously, genes impact individuals' traits, which certainly have some influence on social behavior. The genetic mechanism contributes to social behavior but not with a substantial contribution. Psychological traits impact too on behavior of individual but they are one of many other factors that guide a person to make a decision. Another big component that we should not forget is the freewill. People's attitudes toward innate differences in human appearance - such as skin and hair color, shape and color of eyes, and facial attractiveness - evolve in history and differ between cultures. The semiotician Umberto Eco (2011) argued about the concept on how these phenomena are construct together: the notions of beautiful and ugly are defined in relation to a particular historical period or a particular culture (Eco, 2011). Many social phenomena are based on attitudes toward innate physical features of individuals, such as facial attractiveness, skin color, hair color, congenital physical differences and race. The innate nature of these particularities does not change their essence as social phenomena, and it also does not mean that the innate mechanism of social behavior can exist. For example, race is not an inherited social phenomenon. Racial discrimination is a modern social construct, for until the sixteenth century there was practically nothing in the life and thought of the West that could be characterized as racism (Puzzo, 1964). Race does not even have a physical or biological meaning. Geneticists note that 'the proportion of human genetic variation due to differences between populations is modest, and individuals from different populations can be genetically more similar than individuals from the same population (Witherspoon et al., 2007).

(iii) the conflict with the generally accepted neo- Darwinian evolutionary principles. Even if one assumes that genes impact on traits more than above indicated (in point ii), and therefore the relationship between genes and social behavior is closer than it is, even so, genes can provide inheritance for a very limited number of social phenomena. The cultural development is too fast for natural selection through the genetic mechanism. Social phenomena change faster than genes change through natural selection, so this means that genes encoding the reflection of certain social conventions will be eliminated before being expressed. In a rapidly changing environment, phenotypic flexibility in dealing with different environments is usually preferable to genes that shift the phenotype narrowly toward a particular environment (Burger et al., 2007). For instance, the 'young' 'genetic tolerance in adults for lactose probably arose and spread to high frequencies within the last 6,000 years in some populations of this same language family (Burger et al., 2007)', compared to the 'old' social phenomenon of racial discrimination, which is no more than 600 years old (Puzzo, 1964).

Taking into account the above arguments, the author believes that the acquisition of first social phenomena is still a subject of discussion. The author also believes that any theory of knowledge and/or mind, in order to become acceptable to the academic community, must comply with the laws of physics and be supported by mathematical models. This means that having a deeper understanding of the physical processes of information transfer that underlies initial learning is the goal of current and future researches. The above reflection noted that the attitude of men to some physical features of other individuals is social phenomena acquired in the process of social learning. Therefore, the current review examined social 
interaction of newborns and infants, studying what can help newborns behave socially in different social tasks - (a) recognition of faces: Other Race Effect (ORE), Other Species Effect (OSE), facial attractiveness, and (b) categorization of words - until infants understand enough meanings of phenomena from social reality to initiate social behavior their own.

\section{NEWBORNS AND INFANTS BEHAVE SOCIALLY: FACIAL RECOGNITION}

Over the past 50 years, numerous studies have begun to examine the social behavior of infants through facial recognition. Most of them support results of their identification of parents, women, perception of multiracial faces ORE, other species faces OSE, as well as preference of facial attractiveness. Their findings are crucial for the present review:

(1) Goren et al. (1975) showed that newborn tracked a moving schematic face with a strong preference for the face patterns over the other stimuli (Goren et al., 1975; Johnson et al., 1991).

(2) Newborns demonstrated preference for their mother's face over a stranger's face (Bushnell et al., 1989; Field et al., 1984; Pascalis et al., 1995; Bushnell et al., 2001).

(3) Newborns prefer faces from their own-ethnic group, ORE (Pascalis \& de Schonen, 1994; Kelly et al., 2007).

(4) Preferences of infants depend on their caregivers. Tasting 3- to 4-month-olds infants, Quinn et al. (2002) suggested that 'representation of information about human faces by young infants may be influenced by the gender of the primary caregiver.'

(5) 3-month-old infants prefer the natural composition of inner features of faces rather than the same features, but in an unnatural position. Turati et al. (2005) observed reactions of infants on women pictures. Black-and-white photographs of women's faces have been digitally modified altering the position of internal facial features. Infants saw both normal and modified faces. This study suggested 'that the face arrangement of the inner features in the natural face affects infants' performance, attracting infants' gaze even when face configurations are paired for stimuli equated with up- down asymmetry in the distribution of inner features (Turati et al., 2005 , p. 268)'.

(6) Newborns recognize familiar faces even presented partly. Simion et al. (2007) eliminated one by one inner and internal features from photographs of women's faces found that: '1- to 3-dayold infants are capable of recognizing a familiar face based on either the inner or outer features, and on either featural or configural perceptual properties.'

(7) Newborns prefer attractive faces. 'Human infants prefer to look at physically attractive human faces when they are paired with physically less attractive human faces. Infant preference for attractive faces has been observed for a range of human faces, including Caucasian and African American adult female faces, adult male faces, and infant faces (Quinn et al., 2008).' 'The attractiveness effect can be demonstrated even in newborn infants, is orientation dependent, occurring for upright but not inverted faces, and is driven by the internal features of faces (Quinn et al., 2008).'

(8) The 3- to 4-month-olds infants prefer attractive faces of cats. The results of Quinn et al. (Quinn et al., 2008) demonstrated that 'the preference for attractive faces by infants that has previously been observed for human faces can also be observed for domestic cat faces (Quinn et al., 2008, p. 80).'

(9) The 6- to 9-months-old infants recognize race even through observing grayscale faces in blackand-white photographs. 'Results for the grayscale stimuli showed that even when a salient perceptual cue to race, such as skin color information, is minimized, 6- to 9-month-olds, nonetheless, show an ORE in their face recognition memory. Infants' use of shape-based and configural cues for face recognition is discussed (Anzures et al., 2011, p.641).'

(10) The 3-month-olds infants from cross-race environment did not show ORE. 'African Israeli infants (who by virtue of being a very small ethnic minority experience considerable cross-race exposure) do not develop a preference for own-race faces (Bar-Haim et al., 2006, p. 162).' 
'Biracial infants, however, showed the opposite effect: An 'own-race' novelty preference was associated with reduced scanning between eye and mouth regions of 'own-race' habituation stimuli, suggesting that biracial infants use a distinct approach to processing frequently encountered faces (Gaither et al., 2012, p. 1).'

\section{NEWBORNS AND INFANTS BEHAVE SOCIALLY: WORDS CATEGORIZATION}

Categorization of social phenomena is the skill that allows for social interaction. Adequate interaction with objects depends fundamentally on a person's ability to categorize (Borghi, 2005). How infants bring order into their world by categorizing objects is a core issue for the research in cognitive and language development. Ferry et al. (2010) and then Perszyk and Waxman (2019) found that 3- to 4-month- olds infants already can categorize words - fishes and dinosaurs from different classes - that do not fit into their personal reality. According Danilov and Mihailova (2019): it is necessary to note several circumstances to assess their results:

(i) infants participated at the experiments always with adults: with their caregivers in pair, infants sat on a caregivers' lap facing the stage as well as a supervisor of the experiment, who was there in the contact with infants;

(ii) infants did not perceptually interact with anyone during experiments;

(iii) all persons involved in the experiment - both participants of the pairs infant-caregiver as well as the supervisor - received tasks simultaneously;

(iv) infants improved performance during the experiments when objects were marked vocally that present adult also listened to;

(v) the chosen visual stimuli are fishes and dinosaurs from different classes, that do not fit into the personal reality of 3- to 4-months-old infants (Danilov \& Mihailova, p. 151).

\section{DISCUSSION}

The review evidently shows a discrepancy between the complexity of tasks and ability of infants to solve them. Ten facts from studies on facial recognition and the contradiction from studies on word categorization show infants' social behavior that does not fit with their ability to understand social reality. The beginning of independent assimilation of social phenomena by infants is possible only when a lot of knowledge is already in place: (i) the meaning of 'I', distinct from the environment; (ii) separation of the environment on immovable and movable objects, the retrieval familiar objects from others; (iii) understanding of truth and false, (iv) understanding of the meanings of initial social phenomena, to rely on in order to begin acquiring the meanings of objects from social reality. The analysis of the above noted 11 facts (Sections III and IV) enlightened in the following statements:

- Newborns have very limited knowledge of social reality to behave socially on their own, since their mind does not maintain any communication. Even if one ignores the necessary effectiveness of communication skills to maintain the acquiring social meaning mechanism and assumes that one of the existing hypotheses (or all together) promotes the mechanism of initial learning, then newborns would not have the time to acquire the meanings of enough social phenomenon to understand social reality to such an extent to recognize faces without their context: in schematic pictures (fact 1), distinguishing mother and stranger (fact 2), discriminating race (fact 3 ), recognizing faces through their parts (fact 6), and even selecting attractive faces (fact 7). The research of Danilov and Mihailova argued that at this stage of mental development infants cannot acquire meaning of social reality their own because of lack communication: they initiate to develop their non-verbal communication since 12-months of age (Danilov \& Mihailova, 2019).

- The 3- to 4-month-olds infants cannot independently understand phenomena that are not related to their social reality, which is very limited. The lack of communication noted above does not allow infants to know nature well enough to distinguish attractive cat faces from non-attractive 
ones (fact 8), and to know anatomy well enough to prefer the natural composition of inner facial features rather than the same features, but in an unnatural position, recognizing faces without their context (fact 5). Regarding the fact of word categorization (Section IV), 'infants cannot themselves recognize and classify inappropriate phenomena that are absent or inaccessible to their reality; even if one forgets about the problem of assimilating of first notions and the acquiring of the first words, and supposes that infants somehow themselves have already learned some basic set of meanings, there is another problem of comprehension of abstract phenomena - the above-noted fishes and dinosaurs are not suitable objects for the categorization experiment with 3- to 4-months-old infants; it is very hard to believe that without the help of adults they can categorize such abstract phenomena (Danilov \& Mihailova, p. 155).'

\section{CONCLUSION}

These achievements of infants are possible only through their collaboration with adults. Adults somehow guide infants without any perceptual instruction and/or hints to them. This supposition is also supported by the facts that: the preference of 3- to 4-month-olds infants depends on their caregivers (fact 4); infants from cross-race environment did not show ORE (fact 10); and infants independently can solve tasks even difficult for adults: the 6- to 9-month-olds infants recognize race even through observing grayscale faces in black-and-white photographs (fact 9). Hence, taking all arguments together it is possible to conclude that the initial social learning occurs through non-perceptual social interaction at least partly. One possible explanation for this phenomenon was introduced by Danilov in the theory of Coherent intelligence: 'Coherent Intelligence is an effect of unconscious collaboration provided by interconnection of many brains united by entanglement state of their neurons - the phenomenon of quantum entanglement of particles - which is stimulated by common emotional arousal. This connection of entangled neurons may unite neural chains of different cerebrums and maintain their coherent mental process (Danilov, 2019, p. 109).' This theory supposes that the phenomenon emerges from collaboration of many individuals if they solve an important problem for them at the same time within the framework of single emotional stimulation (Danilov, 2019). Recent research by Danilov and Mihailova (2019) on language acquisition in adults supported this conclusion showing the increase of group performance provided by such unconscious mental collaboration. The theory corresponds to the laws of quantum physics and future research may supplement it with a mathematical model. The long-term study of this rudimental non-perceptual social interaction, which was developed before the emergence of the 5 perceptual senses could complement the understanding of human development within the framework of the modern paradigm of evolutionary theory. The growing field of knowledge and the multicultural environment of its development require improving teaching methods that include higher-order thinking with deeper levels of information processing to create richer memory structures for students. The author believes that long-term studies can help to develop an advanced curriculum based on the non-perceptual social interaction. This method can facilitate learning in various academic disciplines by introducing knowledge even unconsciously while studying the program.

\section{FUTURE WORK}

Recent studies show that group collaboration in problem-solving can significantly increase memorization by $28 \%$, the effect of which increases to $30 \%$ in a month. 'Taking part in a relevant group discussion had a direct positive impact on recall, whilst this positive effect persisted over a longer period only for those who had given explanations during the discussion (van Blankenstein et al., 2011).' This probably means that a learning method based on problem-solving - such as the Problem Based Learning (PBL) method - may suit such a procedure which helps learners to increase implicit memory during solving problems. The crucial point of the PBL is a discovery or insight, which is still inexplicable, unpredictable and uncontrollable process (Boud \& Feletti, 2011). Some recent researches (Colliver, 2000) questioned the efficiency of knowledge acquisition in the PBL. Colliver (2000) argued: 'this review of the research on the

effectiveness of PBL curricula provides no convincing evidence that PBL improves knowledge base and 
clinical performance, at least not of the magnitude that would be expected given the extensive resources required for the operation of a PBL curriculum'. He also summarized that the results of the PBL method to accelerate learning are not significant enough in respect of efforts required. This is considering how many resources the PBL needs to be applied in opposition to the classical learning and also the fact that the speed of this type of learning is less than in the one-to-one tutoring (Colliver, 2000).

Contemporary studies on the PBL method concentrate more its development towards efficiency in criticism training of students rather than to accelerate their knowledge acquisition. Numerous studies, such as one by Rotgans and Schmidt (Rotgans \& Schmidt, 2019), and another one by Masek and Yamin (2011), have shown that the PBL method can effectively help students to develop various abilities such as critical thinking and practical skills (as well as enhance their learning motivation and volition): 'Based on the review, it is concluded that 1) the specific processes in PBL theoretically support students' critical thinking development according to the design applied, 2) empirical evidence in general is inconclusive in explaining the effect of PBL on students' critical thinking ability, especially the studies outside of medical field, 3) some evidence indicates that PBL requires a long term exposure to foster students' critical thinking ability, 4) several predictors might also influence the relationships of PBL and critical thinking such as age, gender, academic achievement, and educational background, which calls for further research work. The implication is that, PBL curriculum must carefully be designed and concerned on the critical elements contributing to PBL effectiveness (Masek \& Yamin, 2011).'

It seems that the modern PBL method is focused on stimulating students to interactive collaboration, by pushing their motivation and interest, which of course is necessary, but does not distinguish clearly the PBL from other methods of training and does not achieve its contemporary goal to accelerate knowledge acquisition. It should be noted that the problem-based essence of the PBL method requires to include in the learning process the actual problem solving activity. This by make students overcoming staged difficulties through their own insight. So not only reaching the solution of simple tasks that doesn't involve cognitive processes of higher-order thinking like the more classic learning methods. The PBL method was established to involve problem solving in the learning process at every stage. 'In PBL, the problem comes first (Schmidt et al., 2019).' The teacher needs to create quite difficult problems to 'switch on' the phenomenon of insight in students. It shouldn't be just a set of tasks as a formal pretext to invite students into an entertaining lesson.

Taking into account all the mentioned above challenges in the contemporary society, the PBL requires confident involvement in its process of high-order thinking with deep levels of information processing and critical thinking skills to achieve success. The author believes that future researches on non-perceptual interaction could be able to develop a PBL method in which teachers can predictably improve the implicit memory of students, incorporating higher-order thinking with deeper levels of information processing in learning. More research is needed to expand our knowledge on non-perceptual social interaction in order to support the development of advanced curriculum based on the PBL method

\section{ACKNOWLEDGMENT}

The paper originally appeared in conference proceedings of Cognitive 2020, ComputationWorld 2020. Copyright (c) IARIA, 2020. ISBN: 978-1-61208-099-4

The author thanks Dr. Sandra Mihailova for her collaboration in research and also expresses his gratitude to Dr. David Vernon and Dr. Tullio Rizzini for their help in preparing this review.

\section{REFERENCES}

Anzures, G., Pascalis, O., Quinn, P.C., Slater, A.M., \& Lee, K. (2011). Minimizing Skin Color Differences Does Not Eliminate the Own-Race Recognition Advantage in Infants. Infancy, 16(6), 640-654. International Society on Infant Studies (ISIS). DOI: 10.1111/j.1532-7078.2010.00066.x

Bar-Haim, Y., Ziv, T., Lamy, D., \& Hodes, R.M. (2006). Nature and nurture in own-race face processing. Psychological Science, 17, 159-163. 
Borghi, A.M. (2005). Object concepts and action. In Grounding Cognition: The Role of Perception and Action in Memory, Language, and Thinking, Edited by Diane Pecher and Rolf A. Zwaan. New York: Cambridge University Press, pp. 8-34.

Boud, D., \& Feletti, G.I. (1997). The Challenge of Problem-based Learning (pp. 40-41). London: Kogan Page.

Burger, J., Kirchner, M., Bramanti, B., Haak, W., \& Thomas, M.G. (2007). Absence of the lactasepersistence-associated allele in early Neolithic Europeans. Proceedings of the National Academy of Sciences USA, 104, 3736-41.

Bushnell, I.W.R. (2001). Mother's face recognition in newborn infants: Learning and memory. Infant Child Dev., 10, 67-74.

Bushnell, I.W.R., Sai, F., \& Mullin, J.T. (1989). Neonatal recognition of the mother's face. British Journal of Developmental Psychology, 7, 3-15.

Colliver, J.A. (2000). Effectiveness of Problem-based Learning Curricula: Research and Theory. Retrieved February 2020, from https://journals.lww.com/academicmedicine/Fulltext/2000/030 00/Effectiveness_of_Problem_based_Learning_Curricula_.17. aspxResults\#pdf-link

Csibra, G., \& Gergely, G. (2009). Natural pedagogy. Trends Cogn. Sci., 13, 148-153.

Danilov, I.Val., \& Mihailova, S. (2019). Social interaction shapes infants' earliest links between language and cognition. Social Sciences Bulletin, 2(29). ISSN 1691-1881, eISSN 2592- 8562

Danilov, I.Val. (2019). Unconscious Social Interaction: Coherent Intelligence (Second edition complemented). [e-book]. Retrieved February 2020, from https://www.amazon.com

Danilov, I.Val. (2020). Ontogenesis of Social Interaction: Review of Studies Relevant to the Fetal Social Behavior. J Med - Clin Res \& Rev., 4(2), 1-7.

Eco, U. (2011). On Ugliness. Maclehose. ISBN 0857051628, 9780857051622

Ferry, A.L., Hespos, S.J., \& Waxman, S.R. (2010). Categorization in 3- and 4-Month-Old Infants: An Advantage of Words Over Tones. Society for Research in Child Development, Inc. https://doi.org/10.1111/j.1467-8624.2009.01408.x

Field, T.M., Cohen, D., Garcia, R., \& Greenburg, R. (1984). Mother- stranger face discrimination by the newborn. Infant Behavior and Development, 7, 19-25.

Gaither, S.E., Pauker, K., \&. Johnson, S.P. (2012). Biracial and monoracial infant own-race face perception: An eye tracking study. Developmental Science, pp. 1-9. DOI: 10.1111/j.14677687.2012.01170.x

Goren, C.C., Sarty, M., \& Wu, P.Y.K. (1975). Visual following and pattern discrimination of face-like stimuli by newborn infants. Pediatrics, 56, 544-1-549.

Johnson, M.H., Dziurawiec, S., Ellis, H., \& Morton, J. (1991). Newborns' preferential tracking of facelike stimuli and its subsequent decline. Cognition, 40, l-19. DOI: 10.1016/0010-0277(91)90045-6

Jones, S.S. (2009). The development of imitation in infancy. Phil. Trans. R. Soc. B., 364, 2325-2335. doi:10.1098/rstb.2009.0045

Kelly, D.J. , Liu, S., Ge, L., Quinn, P.C., Slater, A.M., Lee, K., . . Pascalis, O. (2007) Cross-Race Preferences for Same- Race Faces Extend Beyond the African Versus Caucasian Contrast in 3Month-Old Infants. Infancy, 11(1), 87-95. doi:10.1080/15250000709336871

Masek, A.B., \& Yamin, S. (2011). The Effect of Problem Based Learning on Critical Thinking Ability: A Theoretical and Empirical Review. Retrieved February 2020, from https://www.researchgate.net/publication/266279314_The_Effect_of_Problem_Based_Learning_ on_Critical_Thinking_Ability_A_Theoretical_and_Empirical_Review

Namy, L.L., \& Nygaard, L.C. (2008). Perceptual-motor constraints on sound-to-meaning correspondence in language. Behavioral and Brain Sciences, 31, 5. doi:10.1017/S0140525X08005190

Pascalis, O., de Schonen, S., Morton, J., Deruelle, C., \& Fabre-Grenet, M. (1995). Mother's face recognition in neonates: a replication and an extension. Infant Behavior and Development, 17, 79-85.

Pascalis, O., \& de Schonen, S. (1994). Recognition memory on 3- to 4-day-old human neonates. Neuro Report, 5, 1721-1724.

54 Journal of Higher Education Theory and Practice Vol. 20(12) 2020 
Perszyk, D.R., \& Waxman, S.R. (2019). Infants' advances in speech perception shape their earliest links between language and cognition. Scientific Reports, 9, 3293. https://doi.org/10.1038/s41598-01939511-9.

Plomin, R., DeFries, J.C., Knopik, V.S., \& Neiderhiser, J.M. (2016). Top 10 replicated findings from Behavioral genetics. Perspect Psychol Sci., 11(1), 3-23. doi:10.1177/1745691615617439

Puzzo, D.A. (1964). Racism and the Western Tradition. Journal of the History of Ideas, 25(4), 579-86. doi: $10.2307 / 2708188$

Quinn, P.C., Yahr, J., \& Kuhn, A. (2002). Representation of the gender of human faces by infants: A preference for female. Perception, 31, 1109-1121. DOI:10.1068/p3331

Quinn, P.C., Kelly, D.J., Lee, K., Pascalis, O., \& Slater, A.M. (2008). Preference for attractive faces in human infants extends beyond conspecifics. Developmental Science, 11(1), 76-83. DOI: 10.1111/j.1467-7687.2007.00647.x

Rizzini, T. (2018). The Cultural Linguistic Code. Journal of Life Sciences, 12, 59-63. doi: 10.17265/1934- 7391/2018.01.006

Rotgans, J.I., \& Schmidt, H.G. (2019). Effects of Problem-Based Learning on Motivation. Interest, and Learning. https://doi.org/10.1002/9781119173243.ch7

Schmidt, H.G. , Rotgans, J.I., \& Yew, E.H.J. (2019). Cognitive Constructivist Foundations of ProblemBased Learning. The Wiley Handbook of Problem-Based Learning, p.257. Miley Blackwell.

Silverstein, P., Gligab, T., Westermanna, G., \& Parise, E. (2008). Probing communication-induced memory biases in preverbal T infants: Two replication attempts of Yoon, Johnson and Csibra. Infant Behavior and Development, 55, 77-87. https://doi.org/10.1016/j.infbeh.2019.03.005

Simion, F., Leo, I., Turati, C., Valenza, E., \& Barba, B.D. (2007). How face specialization emerges in the first months of life. Progress in Brain Research, 164. Elsevier B.V., 182. DOI: 10.1016/S00796123(07)64009-6

Tomasello, M. (2003). Constructing a Language: A Usage-Based Theory of Language Acquisition. Cambridge: Harvard University Press.

Turati, C., Valenza, E., Leo, I., \& Simion, F. (2005). Three-month-olds' visual preference for faces and its underlying visual processing mechanisms. Journal of Experimental Child Psychology, 90, 255273. doi:10.1016/j.jecp.2004.11.001

van Blankenstein, F.M., Dolmans, D.H.J.M., Van der Vleuten, C.P.M., \& Schmidt, H.G. (2011). Which cognitive process support learning during small-group discussion? The role of providing explanations and listening to others. Instructional Science, 39(2), 189-204. Retrieved February 2020, from https://link.springer.com/article/10.1007/s11251-009-9124-7

Waxman, S.R., \& Leddon, E.M. (2010). Early Word-Learning and Conceptual Development. The WileyBlackwell Handbook of Childhood Cognitive Development.

Witherspoon, D.J., Wooding, S., Rogers, A.R., Marchani, E.E., Watkins, W.S., Batzer, M.A. \& Jorde, L.B. (2007). Genetic Similarities Within and Between Human Populations. Genetics, 176(1), 351-359. doi: 10.1534/genetics. 106.067355 